\title{
Retraction Note to: Protein-Protein Interaction Network Analysis in Chronic Obstructive Pulmonary Disease
}

\author{
Hong Bao ${ }^{1} \cdot$ Jiaman Wang ${ }^{1} \cdot$ Ding Zhou ${ }^{1} \cdot$ Zhaoyong Han $^{1} \cdot$ Ling Su$^{1} \cdot$ \\ Yuan Zhang ${ }^{1} \cdot{\text { Xiong } \mathrm{Ye}^{1} \cdot \text { Chunyan } \mathrm{Xu}^{1} \cdot \text { Yuping Wang }}^{1} \cdot$ Qinghua $\mathrm{Li}^{1}$
}

Published online: 17 August 2015

(C) Springer Science+Business Media New York 2015

Retraction Note to: Lung (2014) 192:87-93

DOI 10.1007/s00408-013-9509-x

The Publisher and Editor retract this article in accordance with the recommendations of the Committee on Publication Ethics (COPE). After a thorough investigation we have strong reason to believe that the peer review process was compromised.

The online version of the original article can be found under doi:10.1007/s00408-013-9509-x.

Qinghua Li

liqinghua123456@hotmail.com

1 Department of Respiratory Medicine, Shanghai Pudong Hospital, Fudan University Pudong Medical Center, No. 2800

Gongwei Road, Huinan Town, Shanghai 201399, China 